\title{
Multicultural Experiential Learning in Music Therapy Supervision
}

\author{
Jessica Donley ${ }^{1 *}$ \\ 1 Appalachian State University, USA \\ *donleyjm@gmail.com
}

Received: 20 March 2019 Accepted: 29 January 2020 Published: 1 February 2020

Editor: Tríona McCaffrey Reviewers: Paula Higgins, Bill Ahessy

\begin{abstract}
Although music therapists have discussed the importance of multicultural training in supervision, few approaches and applications have been developed to assist music therapy students and professionals in moving towards multicultural competence. Multicultural experiential learning is an approach that supervisors and supervisees can utilize to learn and maintain multicultural skills across the supervision continuum and throughout their careers. This paper explores the responsibilities of supervisors and supervisees who participate in this approach as well as recommendations to determine supervisee eligibility. The role of music in multicultural experiential learning is also discussed to provide opportunities to enhance these types of experiences. Examples of multicultural experiential learning and their instructions are provided for qualified supervisors who want to learn about this approach and implement it in their supervision practice.
\end{abstract}

Keywords: multicultural training, supervision, experiential learning, music therapy

\section{Preface}

According to Hardy and Bobes (2017), supervision "requires extraordinary vision, the ability to look beyond what is spoken, make the invisible visible, and cast a wide net to continually search for all relevant contexts and meanings" (p. 5). Similarly, this paper intends to envision a new process in supervision and contains a collection of ideas from the literature, theories, and the author that may support multicultural competence of music therapists and trainees in music therapy supervision. Although the proposed approach on multicultural experiential learning in supervision has yet to be translated into practice, a previous "practical context" of the approach holds merit as discussed below (Donley, 2018; Stige, 2015, p. 3). The author hopes music therapy supervisors will consider the premise of these ideas for their practice and research, which may shape future theories and practices on music therapy multicultural training (Bruscia, 2012). 


\section{Introduction}

The music therapy field continues to make advancements in multicultural training, but integration of multicultural training and supervision is still needed (Ahessy, 2011; Estrella, 2001; Hadley \& Norris, 2016; Swamy \& Kim, 2019; Whitehead-Pleaux, 2019; Young, 2009). When program curriculums are unable to cover all multicultural topics thoroughly, supervision can address multicultural issues that are historically less prominent in the literature (Ahessy, 2011). If music therapy programs and associations desire to cultivate a strong workforce of multicultural competent music therapists, multicultural training must continue to change to improve clinical outcomes (Sue, 1996; Young, 2009). Multicultural experiential learning may provide this opportunity for change and further integration between multicultural training and supervision.

\section{Multicultural Experiential Learning Defined}

Multicultural experiential learning is defined as "the obtainment of knowledge about multicultural identities and the people within them through experiences within the self or between the self and other that goes beyond conventional classroom learning" (Donley, 2018, p. 5). Multicultural experiential learning gives trainees an opportunity to broaden their awareness of multicultural issues, personally reflect on their worldview, and understand the worldview of individuals from other cultures (Achenbach \& Arthur, 2002; Arthur \& Achenbach, 2002; Bradt, 1997; Brown, 2002). This learning occurs in informal learning environments, such as conferences, religious and member organizations and associations, community events, civic government, and other locations of community engagement for a short period of time. Although short international trips may be considered informal learning by some educators, these trips are not included in the multicultural experiential learning supervision model. Short international trips create more complex learning environments that may make it difficult for individuals to understand and conceptualize systemic issues that impact music therapy clients there. In addition, more research is needed to understand how study abroad and international travel impact exoticism and ethnocentrism in travelers despite mixed findings (Akpovo \& Nganga, 2018; Gullekson \& Tucker, 2013). Multicultural experiential learning varies according to individual and group identities as well as the interactions they have among one another, their clients, peers, supervisor, and environment (Hawkins \& Shohet, 2012). Multicultural experiential learning combines Kolb's experiential learning theory with traditional multicultural training to create teaching applications (Achenbach \& Arthur, 2002; Arthur \& Achenbach, 2002; Donley, 2018; Kim \& Lyons, 2003; Kolb, 2014). Kolb defined experiential learning as the:

aims to create, through a synthesis of the works of the foundational scholars, a theory that helps explain how experience is transformed into learning and reliable knowledge. Truth is not manifest in experience; it must be inferred by a process of learning that questions preconceptions of direct experience, tempers the vividness and emotion of experience with critical reflection, and extracts the correct lessons from the consequences of action. (2014, par. 7)

Simulations utilized in health professions, such as nursing contain similar teaching concepts. However, they are not usually considered multicultural experiential learning, because simulations commonly occur in formal learning environments. Simulations also offer trainees opportunities to relearn a set scenario in a protected and safe environment (Crawley \& Ross, 2017). Unlike simulations, multicultural experiential learning does not provide a chance for trainees to repeat the same experience twice. The process and outcome remain unpredictable (Crowe, 2004). This may be related to the individual's internal process, their surrounding environment, and other factors. These small changes may produce a different outcome from the one originally anticipated (Bruscia, 2014; Crowe, 2004). 
While little evidence-based research exists describing the benefits of multicultural experiential learning, these experiences and knowledge acquired may assist participants in developing cultural humility and cultural empathy (Brown, 2002; WhiteheadPleaux \& Tan, 2017). In turn, these two qualities may further promote continued and advanced cultural competence with lifelong introspective self-reflection (WhiteheadPleaux, 2019). The next section discusses applications of Kolb's experiential learning theory in the counseling and music therapy profession and demonstrates ways to teach multicultural competence while merging theory and practice (Achenbach, \& Arthur, 2002; Arthur \& Achenbach, 2002; Donley, 2018; Kim \& Lyons, 2003).

\section{Multicultural Experiential Learning in the Literature}

Achenbach and Arthur (2002; Arthur \& Achenbach, 2002) discussed experiential learning as a pedagogical approach in multicultural counseling. Role-plays were utilized by researchers as multicultural experiential learning exercises, such as Barnga and Bafa Bafa. Barnga is a card game that assists trainees in understanding cultural issues, such as acculturation, culture shock, and language needs. Participants are divided into groups and given a deck of cards and a set of rules (Steinwachs, 1990; Ushida, Hattori, \& Takdama, 2010). In addition to rules established by the facilitator, each group has their own set of rules. For instance, each group may have a different trump card that wins. Groups play a short game while only communicating nonverbally with their peers. Afterwards, participants move to play peers in other groups. However, participants now have more difficulty determining who wins and loses each turn, because there are multiple rules at play in each group. Achenbach and Arthur (2002) studied Barnga with graduate students in Canada to understand how students perceived multicultural issues. When participants found the experience less purposeful, experiential learning had less of an impact on multicultural competence and was not translated to clinical practice (Achenbach \& Arthur, 2002). Arthur and Achenbach (2002) suggested that emotional responses may assist students in developing competence through gained awareness and reflection. This integration of cognitive and emotional responses is what makes experiential learning unique.

In another experiential learning exercise, Bafa Bafa, participants in two groups embody qualities of a predetermined culture (Arthur \& Achenbach, 2002). Then, each group shares their assigned culture with the other group. Gannon and Poon (1997) suggested that Bafa Bafa promoted students' cultural awareness. In the three multicultural training approaches they researched, they found no differences between integrated, video-based, and experiential learning groups. The researchers, however, reported that participants in the experiential learning group reported higher satisfaction and had more positive responses to the approach. Other examples of experiential learning have included trainees choosing a disability from a list that they would rather live with to 'uncover perceptions about a "hierarchy of abilities"' (Arthur \& Achenbach, 2002, p. 7), having medical and nonmedical staff role-play the experience of inpatients, and a variety of games (Kim \& Lyons, 2003). One of these games is called Step Forward, Step Back, which resembles a modern-day privilege walk (Kim \& Lyons, 2003; Ngoasheng \& Gachago, 2017).

Donley (2018) reflected on her experiences as a music therapist and a participant of multicultural experiential learning in a multicultural counseling course. To understand the socioeconomic, sexual orientation, and religious dimensions of diversity, her professor assigned tasks to course participants. These tasks included acquiring a public assistance application, displaying three behaviors that suggested she identified as a different sexual orientation, and attending a prayer at a Muslim mosque. Following each task, the professor facilitated a discussion around the group's experiences. This case example carries important implications for multicultural training in music therapy. The author's reflexivity on multicultural experiential learning as a White female therapist may encourage other White females, the majority identity of music therapists, to participate. This may also create more allies for minority music therapists and 
promote equity in the profession. In addition, the task descriptions and author's reflexive writing may encourage other music therapists to develop multicultural experiential learning or similar tools for themselves, students, or supervisees (Whitehead-Pleaux, 2019). This would provide a wealth of resources for future music therapists.

Although this case example carries important implications, there are still many unknowns. First, it remains uncertain how music therapists with other intersectional identities perceive this method. It is also uncertain how multicultural experiential learning impacts supervisees long-term (Arthur \& Achenbach, 2002). When students perceive this type of learning as negative, their perception may also remain negative post-experience. For this reason, it is possible that multicultural experiential learning may decrease multicultural competency in some students. For instance, in Brushke, Gartner, and Seiter (1993), student views of ethnocentrism increased. Similar results were found in another study where an experiential learning exercise promoted competition instead of cultural empathy (Barak, 1990). This demonstrates the delicate nature of implementing experiential learning. Despite the sensitivity involved, helping professionals must not shy away from this potentially beneficial tool in multicultural training. Instead, organizations and their member clinicians must have an acute awareness and precision of multicultural skills and recognize their responsibilities when implementing and choosing experiential learning exercises (Arthur \& Achenbach, 2002).

\section{Organization Responsibilities}

Organizations have a responsibility to their members and employees as well as their students, interns, and volunteers. These organizations set the directive for professional and advanced competencies, standards of practice, codes and ethics, and policies and procedures. According to the seven-eyed model of supervision, as part of the seventh mode, organizational requirements influence the decisions and direction that supervisees and supervisors pursue together in the supervisory and client relationship (Hawkins \& Shohet, 2012). Due to organizations' possible influence on multicultural competence and multicultural experiential learning in supervision practice, the author researched international music therapy organization and association websites to identify expectations for credentialed music therapists. Music therapy organizational websites were located using the American Music Therapy Association, World Federation of Music Therapy, European Music Therapy Federation, and Google websites. When a music therapy organizational website was in the author's non-native language, the author utilized Google translate in Google Chrome to identify multicultural issues within their Code of Ethics and Standards of Proficiency. All associations that provided directives on multicultural training and supervision were included in this paper. The author also reviewed the American Counseling Association's resources, which provided an important guide in a similar article (Donley, 2018). The author was unable to access several websites that were out of date. In a few instances, the author managed to access the website but still had difficulty accessing information without login information. The author emailed organizations that provided contact information.

According to the American Music Therapy Association's advanced competencies, music therapists are encouraged to "apply knowledge of norms and practices of diverse cultures to the supervisory process" (American Music Therapy Association, 2015a, par. 5). The Canadian Music Therapy Association (2002) stated more generally that music therapists are obligated to "facilitate the professional development of their students, interns, and employees assuring that these persons understand the values and ethical standards of the profession, and by providing or arranging for...opportunities for experience" (p. 17). The European Music Therapy Confederation, which comprises of 44 member associations, addressed equal opportunity and access for clients, trainees, and professionals in its ethical code (European Music Therapy Confederation, 2005). Unfortunately, there were no specific directives on multicultural training and supervision that were able to be located on the confederation or any of their member associations' websites. Although not specific to multicultural training and supervision, the 
Table 1

Sections from Music Therapy Organizations' Code of Ethics

\begin{tabular}{|c|c|c|}
\hline Organization & Sections & Description \\
\hline $\begin{array}{c}\text { American Music Therapy } \\
\text { Association }\end{array}$ & 1.8 & $\begin{array}{r}\text { acquire knowledge and information about the specific cultural } \\
\text { group(s) with whom they work, seeking supervision and education } \\
\text { as needed. }\end{array}$ \\
\hline $\begin{array}{c}\text { American Music Therapy } \\
\text { Association }\end{array}$ & 2.6 & $\begin{array}{r}\text { seek peer/professional supervision to assist with reflection and } \\
\text { practice improvement. }\end{array}$ \\
\hline $\begin{array}{c}\text { American Music Therapy } \\
\text { Association }\end{array}$ & 4.2 & $\begin{array}{r}\text { use resources available to them to enhance and better their prac- } \\
\text { tice (e.g., peer/professional supervision). }\end{array}$ \\
\hline $\begin{array}{c}\text { American Music Therapy } \\
\text { Association }\end{array}$ & 5.3 & $\begin{array}{r}\text { use caution, critical thinking, and strong consideration of the best } \\
\text { available evidence when incorporating new and evolving interven- } \\
\text { tions and technologies into their practice, education, or supervi- } \\
\text { sion. }\end{array}$ \\
\hline
\end{tabular}

Irish Association of Creative Arts Therapists and YAHAT, Israel Association for Creative Arts Therapies (abbreviated for "Creation, Expression, Therapy" in Hebrew) addressed cultural issues more in depth by requiring therapists and members to study, develop, and acquire knowledge of cultures different from their own (Irish Association of Creative Arts Therapists, 2005; YAHAT, n.d.). The American Music Therapy Association has followed the American Counseling Association's lead with a newly revised Code of Ethics (American Music Therapy Association, 2019). Supervisors who want to implement multicultural experiential learning need to review and uphold this ethical code. According to Dileo (2000), "one can go so far as to question whether it is ethical not to include experiential training in the music therapy curriculum" (p. 244) It must also be ethical then to include multicultural experiential training in the music therapy curriculum particularly with practicum and clinical training. See Table 1 below for initial guidance of ethical considerations in multicultural experiential learning.

Other music therapy professional organizations should consider including more specific language in their ethical codes and competencies to encourage members and future clinicians to integrate multicultural training with supervision practice. Currently, the music therapy literature offers only a few models and best practices for this integration (Norris \& Hadley, 2019; Swamy \& Kim, 2019; Whitehead, 2019). Multicultural experiential learning is an approach that may assist trainees and professionals at all levels of supervision to become more competent in multicultural skills. Through this approach to multicultural training, supervisors can adapt traditional supervision models derived from colonialist ideals (Comte, 2016; Estrella, 2001).

\section{Supervisor Responsibilities}

Although several music therapy associations and organizations lack multicultural training language in their code of ethics or standards of practice, they describe responsibilities of the supervisor, which are critical to the implementation of multicultural experiential learning (American Music Therapy Organization, 2015b; Australian Music Therapy Association, 2014; Canadian Music Therapy Association, 2002; New Zealand Music Therapy Association, 2012). The following sections of organizations' resources are just a few that apply:

Supervisors and university program directors must responsibly consider aspects of this multicultural training tool before implementing with trainees. One of these considerations is that multicultural experiential learning must align with competencies and advanced competencies (American Music Therapy Association, 2013; American Music Therapy Association, 2015a; Arthur \& Achenbach, 2002). According to Hardy (2017), supervisors also have the option of aligning multicultural experiential learning with 
Table 2

Sections from Music Therapy Organizations' Resources on Supervisor Responsibilities.

\begin{tabular}{|c|c|c|c|}
\hline Organization & Reference & Sections & Description \\
\hline $\begin{array}{l}\text { American Music Therapy } \\
\text { Association }\end{array}$ & $\begin{array}{l}\text { Standards } \\
\text { of Clinical } \\
\text { Practice }\end{array}$ & 8.2 & $\begin{array}{l}\text { It is the responsibility of the Music Therapist providing supervision to maintain } \\
\text { knowledge of current developments in research, theory, and techniques in music } \\
\text { therapy supervision and supervision in general. }\end{array}$ \\
\hline $\begin{array}{l}\text { American Music Therapy } \\
\text { Association }\end{array}$ & $\begin{array}{l}\text { Standards } \\
\text { of Clinical } \\
\text { Practice }\end{array}$ & 8.2.1 & $\begin{array}{l}\text { The Music Therapist providing supervision will be familiar with current federal, } \\
\text { state, and local laws as well as the AMTA Code of Ethics as they pertain to supervi- } \\
\text { sion and confidentiality within supervision. }\end{array}$ \\
\hline $\begin{array}{l}\text { American Music Therapy } \\
\text { Association }\end{array}$ & $\begin{array}{l}\text { Standards } \\
\text { of Clinical } \\
\text { Practice }\end{array}$ & 8.2.2 & $\begin{array}{l}\text { The Music Therapist providing supervision is required to will adhere to all AMTA } \\
\text { Standards of Clinical Practice and will assure that the Music Therapist supervisee } \\
\text { has read and agrees to adhere to the AMTA Standards of Clinical Practice. The Mu- } \\
\text { sic Therapist providing supervision shall hold the supervisee accountable for ad- } \\
\text { hering to the AMTA Standards of Clinical Practice. }\end{array}$ \\
\hline $\begin{array}{l}\text { Australian Music Therapy } \\
\text { Association }\end{array}$ & $\begin{array}{l}\text { Standards } \\
\text { of Clinical } \\
\text { Practice }\end{array}$ & 4.4 & it. \\
\hline $\begin{array}{l}\text { Australian Music Therapy } \\
\text { Association }\end{array}$ & $\begin{array}{l}\text { Code of } \\
\text { Ethics }\end{array}$ & 4.8 & $\begin{array}{c}\text { Registered Music Therapists in supervising the work of students have a responsi- } \\
\text { bility to model and promote awareness of, and adherence to, the provisions of } \\
\text { this Code, particularly regarding confidentiality }\end{array}$ \\
\hline $\begin{array}{l}\text { Canadian Music Therapy } \\
\text { Association }\end{array}$ & $\begin{array}{l}\text { Code of } \\
\text { Ethics }\end{array}$ & I.1 & $\begin{array}{l}\text { Demonstrate respect for the dignity, worth, experience, and knowledge of all peo- } \\
\text { ple }\end{array}$ \\
\hline $\begin{array}{l}\text { Canadian Music Therapy } \\
\text { Association }\end{array}$ & $\begin{array}{l}\text { Code of } \\
\text { Ethics }\end{array}$ & 11.2 & $\begin{array}{l}\text { Avoid doing harm to clients, students, research participants, colleagues, and oth- } \\
\text { ers. }\end{array}$ \\
\hline $\begin{array}{l}\text { Canadian Music Therapy } \\
\text { Association }\end{array}$ & $\begin{array}{l}\text { Code } \\
\text { Ethics }\end{array}$ & 11.7 & $\begin{array}{l}\text { Keep themselves up to date with relevant knowledge, research methods, and } \\
\text { techniques, through the reading of relevant literature, peer consultation, supervi- } \\
\text { sion, and continuing education activities. }\end{array}$ \\
\hline $\begin{array}{l}\text { Canadian Music Therapy } \\
\text { Association }\end{array}$ & $\begin{array}{l}\text { Code of } \\
\text { Ethics }\end{array}$ & III.15 & $\begin{array}{l}\text { Act on their obligation to facilitate the professional development of their stu- } \\
\text { dents, interns, and employees by assuring that these persons understand the val- } \\
\text { ues and ethical standards of the profession, and by providing or arranging for ad- } \\
\text { equate working conditions, timely evaluations, constructive consultation, and op- } \\
\text { portunities for experience. }\end{array}$ \\
\hline $\begin{array}{l}\text { New Zealand Music Ther- } \\
\text { apy Registration Board }\end{array}$ & $\begin{array}{l}\text { Standards } \\
\text { of Practice }\end{array}$ & 9(c) & treat all persons with dignity and respect; \\
\hline $\begin{array}{l}\text { New Zealand Music Ther- } \\
\text { apy Registration Board }\end{array}$ & $\begin{array}{l}\text { Standards } \\
\text { of Practice }\end{array}$ & 10(a) & demonstrate the ability to establish and maintain a safe practice environment; \\
\hline $\begin{array}{l}\text { New Zealand Music Ther- } \\
\text { apy Registration Board }\end{array}$ & $\begin{array}{l}\text { Standards } \\
\text { of Practice }\end{array}$ & $10(e)$ & $\begin{array}{l}\text { be committed to regularly updating, reviewing and documenting clinical knowl- } \\
\text { edge and skills through a variety of professional development opportunities. }\end{array}$ \\
\hline
\end{tabular}

multicultural topics, such as family, gender, religion, sexual orientation, race, socioeconomic status, and intersectionality to name a few.

Supervisors also fulfill extensive and multiple roles in multicultural experiential learning. According to Vasquez (1992), supervisors model ethical practice through their expertise and training. At a minimum, it is recommended that supervisors take two advanced level courses and participate in any multicultural experiential learning exercises prior to presenting them to their supervisees (Vasquez, 1992). Each year, the University of the West of England holds an advanced level course on supervision training one day a month. This supervision training includes multicultural issues, educational factors in supervision, and ethical and professional requirements that apply to participants' contexts (University of the West of England, 2019). One example of a potential multicultural experiential exercise that the author located on the British As- 
sociation for Music Therapy website was the Céilí \& Gala Buffet, which is offered during their upcoming 2020 conference (British Association for Music Therapy, n.d.). The event includes a buffet supper and Irish dancing with a live band and caller. This traditional form of Irish dancing dates back to the 1500s (https://www.ceilidancing.com/, n.d.). These advanced level courses and experiences provide settings for critical and higher conceptual level of thinking. Murphy (2019) wrote that supervisors' ethical responsibilities include having the knowledge of cultural complexities in supervision and clinical practice and creating an exploratory space for dialogue on cultural complexities and differences.

Supervisors also model cultural humility and cultural empathy. According to Whitehead-Pleaux \& Tan (2017), "Cultural competence comes from a place of humility, genuine interest, and seeking to understand how another person's culture influences their worldview and the way in which they live their lives" (p. 273). The supervisor assumes these qualities recognizing that they cultivate and stem from cultural competence (Whitehead-Pleaux \& Tan, 2017). Other beneficial skills for the ethical practitioner include multicultural counseling and group processing for when strong feelings and emotions arise in the supervisory process (Donley, 2018; Hardy \& Bobes, 2017). In addition to these requirements, the supervisor supports and validates the supervisee's experience by creating and holding a safe space (Feiner, 2001; Hardy \& Bobes, 2017). Supervisors remain transparent about expectations with supervisees that multicultural experiential learning is voluntary and will not affect their performance evaluation or grade (Dileo, 2000). The supervisor's responsibility does not include the overseeing of the supervisee's participation in multicultural experiential learning. Instead, an overall evaluation of the supervisee's multicultural competency may be completed for gatekeeping purposes if later deemed necessary (Forinash, 2000). The supervisor also helps supervisees to develop sustainable practices in multicultural learning by first setting a foundation and allowing the supervisee to explore outward from the initial safety net that was introduced.

Supervisors must consider other roles as well, such as teacher, counselor, consultant, and cultural facilitator (Dileo, 2001; Feiner, 2001; Hardy \& Bobes, 2017; Neufeldt, 1999; Stige, 2001). The supervisor balances these roles to address the unique supervision needs of the trainee (Stige, 2001). In the roles of teacher and therapist, the supervisor guides difficult dialogue with the supervisee or supervisees. This allows supervisees to learn these skills through a professional and personal process, which supports Dileo's (2001) intention for supervision. Supervisors may also need to fill the role of consultant for supervisees who have a greater awareness of their cultural identity and multicultural issues. These may be supervisees from underrepresented or marginalized groups who have faced oppression. In this role of consultant for multicultural training, the supervisor can enter into an alliance with the supervisee (Neufeldt, 1999; Swamy, 2011). This alliance encourages a greater displacement of power to the supervisee and more opportunity for supervisors to seek cultural humility (Forinash, 2000; Neufeldt, 1999; Swamy, 2011; Whitehead-Pleaux \& Tan, 2017). When supervisors act as the "listening coauthor" and "not-knowing listener" as titled by Stige (2001, p. 164-166), power can shift to the supervisee who begins formulating independent conclusions from their own knowledge and developing independent reflexivity. Validation is vital for the student, especially after the student forms conclusions following their first multicultural experiential learning task. This validation will support them in their lifelong multicultural learning process (Donley, 2018; Orozco et al., 2014).

\section{Eligible Supervisees}

Before introducing the multicultural experiential learning tool, supervisors should evaluate the supervisees' strengths, needs, level of supervision, and competencies. Supervisees who are willing to listen and participate are the most desired. It is also helpful for supervisees to already have a working knowledge of the cross-cultural and multicultural literature. Supervisees in their first practicum, the beginning of their intern- 
ship, or a new professional position may not be the best candidates for participation. These phases are more likely to be filled with transition and readjustment while the trainee develops their identity and foundation within the profession. Supervisees identified with severe professional competency problems are encouraged to address priority competency areas first (Hsiao, 2014). Then, the supervisee may reenter the multicultural learning process (Hadley \& Norris, 2016). Supervisees with problematic behaviors may benefit if they experience "discomfort with various types of diversity in clients" (Dileo, 2001, p. 34). Supervisors must carefully evaluate supervisees in this instance to measure potential gains for that individual as well as risks to others.

\section{Supervisee Responsibilities}

In some cases, such as with the Canadian Association of Music Therapy (2002), music therapy students and supervisees are required to uphold the same responsibilities as credentialed music therapists. Within this and other associations, the supervisor remains responsible for the professional obligations of their supervisee (American Music Therapy Association, 2015a; Canadian Music Therapy Association, 2002). The supervisor also needs to communicate these responsibilities and guide the supervisee to the appropriate resources.

\section{Across the Supervision Continuum}

Multicultural experiential learning can be utilized at different times in training and program curriculums to meet the unique supervision needs of trainees (Arthur \& Achenbach, 2002; Feiner, 2001). Although it is unclear when it would be most effective to introduce to trainees, multicultural experiential learning addresses a need for the continuation of multicultural competence (Arthur \& Achenbach, 2002; Donley, 2018). Bernard (1994) suggested "supervision is not an appropriate place for an awareness of multicultural dynamics to begin-not for the trainee, and especially not for the supervisor" (p. 160). Bernard's suggestion is valid, but multicultural ethical issues may arise due to a lack of multicultural competency. During these cases, supervisors must take immediate action for remediation (Bradt, 1997). Because Bernard's (1994) statement remains unclear to the supervision type involved, certain types of supervision may be more appropriate than others. This may include pre-professional supervision, internship supervision, professional supervision, group supervision, and peer supervision. Multicultural experiential learning may have positive implications for the majority White female workforce in music therapy (Hadley \& Norris, 2016). Using a parallel process in supervision, multicultural experiential learning could develop competence in the supervisor and supervisee, especially when didactic models of multicultural training may not be as effective alone (Arthur \& Achenbach, 2002; Dileo, 2000; Forinash, 2001; Kim \& Lyons, 2003).

\section{Preprofessional Supervision}

In preprofessional supervision, supervisors will need to make several considerations for offering multicultural experiential learning with students and interns. In general, it is recommended that student trainees in their final year of clinical training, or interns in their final two months of clinical placement or internship be approached with this opportunity. By then, it is estimated that trainees will have the groundwork for clinical practice as well as tools and resources available to them from which multicultural experiential learning may be built upon. This will depend on each supervisee, and on clinical requirements that may vary internationally. Terminology for clinical requirements may also vary internationally in different countries as well as organizations (Hawkins \& Shohet, 2012). The supervisor acknowledges this difference and determines when students at their site or at the institutional level have laid the clinical groundwork. 


\section{Institutional Supervision}

Supervisors' determination of utilizing multicultural experiential learning in this setting will depend on their assessment of eligible supervisees. In some cases, supervisors and program directors may find that designations for undergraduate or graduate students are helpful. However, this is not a designation that can be relied upon. When supervisors supervise a dyad or group of student trainees, it would be best for the supervisor to assess trainee eligibility and only include this approach if all are determined eligible. If introduced to select trainees, these select trainees may feel targeted. For other trainees, they may desire the opportunity to participate and be concerned about their clinical skills and abilities. In extraordinary cases, such as problem behaviors with client diversities; the supervisor may choose to introduce the learning opportunity to a trainee during a private meeting. Graduate student supervisors who have less than two years clinical experience and one year of supervising are not recommended as institutional facilitators of this approach.

\section{Internship Supervision}

Supervisors may facilitate multicultural experiential learning at the internship level. Because internship creates many new challenges for the supervisee, the supervisor must be careful to offer a choice in the process (Feiner, 2001). Supervisees already are given few choices at their internship. Although each intern is unique in their needs at internship, it is recommended that the supervisor wait to incorporate multicultural experiential learning during the "structure building" or "reciprocity and well-being" (Chazan, 1990, p. 110-112) phases prior to termination. During these phases, the intern has become more independent. It is also helpful when the supervisor has established trust with the supervisee. Multicultural experiential learning must be allowable hours towards the intern's required clinical hours.

\section{Professional Supervision}

In professional supervision, supervisors may facilitate multicultural experiential learning and offer space for supervisees to discuss those experiences. However, because this career phase is marked with greater autonomy and independence, supervisees may determine their eligibility and seek out these opportunities on their own. Professional music therapy supervisees are expected to have a level of awareness that helps them to adhere to their organizations' standards of practice, code of ethics, and professional competencies while also acknowledging areas they need to address in clinical practice and outside events that may impact this work. This awareness may also assist professional supervisees by determining the best time for multicultural experiential learning participation, especially when working with a new population, theirs or clients' stuckness, or during difficult seasons of life. Professional music therapists may also participate individually or with other colleagues outside of professional supervision. If through individual participation, music therapists need to consider how they will process their experience. Some options may include reflexive writing, songwriting, musical improvisation, music playing, and sharing in professional supervision or personal therapy. Supervisees may also seek out multicultural experiential learning opportunities at conferences or continuing music therapy education events. These opportunities provide professional supervisees avenues for engaging with diverse music therapists and trainee participants. In some cases, it may be beneficial for the music therapist supervisee and music therapist supervisor to participate in multicultural experiential learning either separately or together and process their experiences together. This may promote the parallel process mentioned earlier (Arthur \& Achenbach, 2002; Dileo, 2000; Forinash, 2001; Kim \& Lyons, 2003). 


\section{Group Supervision}

In group supervision, supervisors and supervisees can structure multicultural experiential learning in several ways. Supervisees can choose to complete these experiences as an individual, in pairs, or groups. The supervisor should challenge the supervisee to explore their decision about how to participate if they repeatedly choose the same option out of comfort. For instance, therapists who often choose to participate in a group may gain greater insight by participating in experiential learning independently. In addition to this role and others previously listed, supervisors may also serve as moderator to help make the group cohesive in group supervision settings (Frohne-Hagemann, 2001). Processing multicultural experiential learning in group supervision offers music therapists and trainees insights to "different theoretical and philosophical approaches" (Frohne-Hagemann, 2001, p. 233).

\section{Peer Supervision}

In some cases, traditional music therapy supervision may not be available to music therapists, especially those in developing countries. There, the therapist is the sole therapist or one of only a few in that area (Stige, 2001). Likely, these music therapists have to rely on Internet communication. In these instances, multicultural experiential learning may be challenging and differ significantly based on the context of the therapists (Hardy, 2017). Peer supervision will also differ structurally needing a designated individual to redirect the group during dialogue and discussion. Typically, peer supervision has "no single overseer" (Baratta, Bertolami, Hubbard, MacDonald, \& Spragg, 2001, p. 183), and the group carries the responsibility of the direction of the group. For this reason, clear boundaries are strongly recommended. Music therapists transitioning from university to early career positions may also benefit from multicultural experiential learning in peer supervision, because it is an affordable means for accountability in the field. It is important for early career therapists and others in their peer supervision group to assess early career music therapists' level of awareness and foundation in the workplace prior to implementation. The overseer is critical for any peer supervision group desiring to participate in multicultural experiential learning followed by group discussion. Group dynamics can be challenging and may vary depending on individuals with similar or dissimilar mindsets.

\section{Using music}

As a field that uses music as a method (Clark, 2002), music is already ingrained as a learning experience. Langdon (2001) even gave his model of professional supervision the name experiential music therapy program. In this approach Langdon stated, 'One of the most important needs for support is in nurturing the way of thinking that allows us to move back and forth between words and music, and particularly, being able to nurture what can be called the "musical mind"' (p. 211). This blend gives supervisees an opportunity to move back and forth between the music experience and verbal processing, which "greatly enhances the opportunities to explore connections between thoughts and feelings, actions and reactions, and so forth" (Hardy \& Bobes, 2017, pp. 6-7). This proposed model of supervision has the potential to use multicultural experiential learning exercises with a synthesis between experiences, verbal processing or debriefing, and music. Through this triangular synthesis, a supervisee can develop a mind that has greater awareness for multicultural issues in our field. The supervisor or supervisee may integrate music in multiple forms according to Langdon's model of supervision. Music can solely be used before, after, or before and after the multicultural experiential learning exercise. Songwriting, improvisations, lyric discussion, singing, and movement to music may all be utilized in addition to other forms not listed here. Those listed below are just a few of many possibilities for the supervisor and supervisee. 


\section{Songwriting}

Supervisees may choose to utilize songwriting to process a multicultural experiential learning exercise after it occurs. For instance, supervisees can write a song or songs using words from themselves or an entire supervision group that musically expresses what was experienced. Supervisees may also choose to incorporate lyrics from persons they interacted with or observed. If supervisees participated in an exercise involving music or a musical event, supervisees can include musical elements from that experience to write a song.

\section{Improvisations}

Prior to the multicultural experiential learning exercise, supervisees may improvise musically. Supervisors may find this helpful in understanding the current feelings and thoughts of supervisees related to the upcoming experience. According to Eyre (2019), the use of music may also offer important information about supervision direction in addition to therapeutic direction. Music provides an outlet for supervisees to express anxiety or other feelings and dive deeper. This may also give supervisees a greater awareness of their feelings related to safety prior to participation. Improvisations may also be beneficial post-experience. When supervisees are not able to identify words that speak to their experience, they can use music. In particular, it may be helpful for supervisees with an incongruent affect with what they are expressing verbally. Improvisations also have the ability to meet all of the expressive and processing needs of one supervisee or an entire group.

\section{Lyric discussions}

Supervisees can choose a song that they believe aligns with a multicultural experiential learning exercise. Supervisees may make this determination using the song's history, lyrics, musical qualities, or other elements. Prior to the exercise, the supervisee can discuss with the supervisor or other supervisees their impression of the song, why they chose it, and how it coincides with the exercise. During the exercise, supervisees are asked to remain conscious of the song. Afterwards, supervisees report their experience and insights in connection with the song. In addition to this example, supervisees also have the option to bring a song post-experience that represents their experience or how they feel.

\section{Singing}

Although this is not limited to singing, supervisees who have felt that they lost their voice as a result of racism, oppression, prejudice, and other systemic disadvantages; may re-experience similar feelings when participating in multicultural experiential learning. A supervisee or supervisor with their intuition and good judgement may identify a song for the supervisee to sing in a supervisory or private setting depending on the depth of process needed. Singing repetitious song lyrics may also affirm the supervisee's experience bringing it greater value and meaning.

\section{Movement to music}

Some supervisees may prefer a different form of expression, such as movement. A supervisor can play music while the supervisee or supervisees move expressively to process their experience. A group can also choose to collectively create a movement work together. In addition, supervisees can direct others, such as supervisees and the supervisor how to move based on their own experience completing the exercise.

\section{Music Imagery}

Music imagery interventions, such as the Bonny Method of Guided Imagery and Music (BMGIM) may provide powerful opportunities for multicultural experiential learning 
Table 3

(American Music Therapy Association, 2013; Hardy \& Laszloffy, 1995)

\begin{tabular}{|c|c|c|}
\hline $\begin{array}{c}\text { Multicultural } \\
\text { learning } \\
\text { experience }\end{array}$ & Competencies addressed & Possible modifications \\
\hline $\begin{array}{c}\text { 1. Develop } \\
\text { your cultural } \\
\text { genogram }\end{array}$ & $\begin{array}{c}\text { 9.5 Demonstrate awareness of the influence of } \\
\text { race, ethnicity, language, religion, marital sta- } \\
\text { tus, gender, gender identity or expression, } \\
\text { sexual orientation, age, ability, socioeconomic } \\
\text { status, or political affiliation on the therapeu- } \\
\text { tic process. }\end{array}$ & $\begin{array}{c}\text { In group supervision, supervisees could } \\
\text { help each other to create their cultural } \\
\text { genogram. This could encourage cultural } \\
\text { empathy with peers that may create a } \\
\text { parallel process with clients in music } \\
\text { therapy practice. }\end{array}$ \\
\hline
\end{tabular}

participants to move through aspects of the multicultural experiential learning exercise again. While the supervisee will not re-experience the multicultural experiential learning exercise in the same way, the BMGIM session may serve to make the unconscious conscious for supervisees or supervisors (Bruscia, 2002). It is recommended that a supervisee seek out their own therapist for BMGIM to avoid dual relationships in supervision. Other forms of music imagery, such as Guided Imagery and Music may also be helpful to the supervisee and easily accessed with online resources and applications.

When using music to enhance multicultural experiential learning, it would be wise for supervisors and supervisees to discuss comfortableness and boundaries. Supervisors and supervisees may prefer to utilize music outside of the supervision setting and during clinical work with clients only. For some, using music to process multicultural experiential learning may be a better fit with their personal therapist, counselor, or clinician.

\section{Online supervision}

For online supervision, integrating music into the process for multicultural experiential learning may have its challenges. Recording and audio devices may not provide the best music or sound quality. The musical space shifts when supervisor and supervisees are unable to be present together. Other creative arts, such as the expressive arts may be more beneficial for this type of supervision.

\section{Examples of Multicultural Experiential Learning}

Two examples of multicultural experiential learning are found below that may be modified to meet the needs of supervisees in individual, peer, group, or self-supervision. The first multicultural experiential learning exercise may be a great starting point for supervisees or supervisors who may be new to multicultural training. This experiential learning facilitates awareness of the supervisees' and supervisors' cultural identity and its relationship to other individuals in their context.

\section{Directions}

Using Hardy and Laszloffy (1995) as a resource, the supervisee will design their own cultural genogram that defines their culture. The supervisee will record any responses they find meaningful including thoughts and feelings they have in creating their genogram. The supervisee has the option of sharing their cultural genogram with their supervisor. Following the creation of a cultural genogram, the supervisee is encouraged to attend a cultural event in their community or a neighboring community that represents an aspect of their cultural identity. Following this cultural event, the supervisee is encouraged to attend a cultural event in their community that represents a culture identity different from their own. Cultural events may include festivals, concerts, and marches. The supervisee should keep a journal of their thoughts and feelings in reflection of these experiences to promote their cultural competence. 
Table 4

(American Music Therapy Association, 2013; American Music Therapy Association, 2015a; N. Jordan, personal communication, August 22, 2017).

\begin{tabular}{|c|c|c|}
\hline $\begin{array}{c}\text { Multicultural } \\
\text { learning } \\
\text { exercise }\end{array}$ & Competencies addressed & Possible modifications \\
\hline $\begin{array}{l}\text { 2. Attend a } \\
\text { Muslim } \\
\text { mosque ser- } \\
\text { vice1 }\end{array}$ & $\begin{array}{l}\text { Professional competencies: } \\
\text { 9.5 Demonstrate awareness of the influence } \\
\text { of race, ethnicity, language, religion, marital } \\
\text { status, gender, gender identity or expression, } \\
\text { sexual orientation, age, ability, socioeconom- } \\
\text { ic status, or political affiliation on the thera- } \\
\text { peutic process. } \\
\text { Advanced competencies: } \\
\text { as indicated. } \\
\text { of diverse cultures to the supervisory process } \\
\text { as } \\
\text { based on knowledge of and sensitivity to the } \\
\text { roles and meanings of musics in diverse cul- } \\
\text { tures. } \\
\text { 8.8 Work with culturally diverse populations, } \\
\text { applying knowledge of how culture influ- } \\
\text { ences issues regarding identity formation, } \\
\text { concepts of health and pathology, and un- } \\
\text { derstanding of the role of therapy. }\end{array}$ & $\begin{array}{l}\text { Instead, supervisors or supervisees could } \\
\text { attend another religious service, such as } \\
\text { at a Christian church, Jewish temple, or } \\
\text { another place of worship that would help } \\
\text { them understand the experience of super- } \\
\text { visees or clients. }\end{array}$ \\
\hline
\end{tabular}

After the supervisee has gained an awareness of different aspects of their cultural identity, such as race, ethnicity, gender, and sexual orientation, the following exercise may be beneficial in encouraging an awareness of the supervisee's spiritual and religious identity. This exercise could be helpful for supervisees working with individuals of different spiritualties and religions. It can be modified accordingly.

\section{Directions}

The supervisee will attend a service at a Muslim mosque. It is up to the participant's discretion to choose how they want to participate within the service. The supervisee must practice cultural empathy while in attendance and maintain an awareness of unearned advantages they hold in connection with this dimension of diversity. The supervisee may find it helpful to conduct their own research prior to their attendance of a religious service that is outside their own spiritual and religious identity. Following the experience, the supervisee will reflect on the experience by sharing their thoughts and feelings while attending. The supervisee will utilize the following prompts as a way of processing the experience:

- How would you define your cultural identity in relation to this experience?

- Describe your experience as well as any thoughts and feelings they came to your awareness.

- How may this experience support your clinical work with clients? How may this experience support your supervisory work with supervisees?

According to Hardy and Laszloffy (1995), there may be limitations to these experiential learning exercises for some individuals. For instance, some family systems are extensive in some cultures. Some trainees may also not have the ability to trace their 
cultural background due to adoption, immigration, or other historical events, such as the transatlantic slave trade.

\section{Conclusion}

Since music therapists at all professional levels utilize supervision, supervision may be an ideal conduit for developing and maintaining multicultural competence. This may ease the pressure off of university programs to develop new courses and compact information into already hearty curriculums. To date, few applications that combine multicultural learning and supervision practice have been identified. Multicultural experiential learning in supervision may fulfill this pressing need in music therapy and other helping professions. Unique to this proposed supervision model is its ability to synthesize multicultural experiences, verbal dialogue and reflection, and music. As a result of this triangular synthesis, participants may be more likely to gain qualities necessary to reach multicultural competence including cultural humility, cultural empathy, and multicultural awareness. Despite this model's potential to transform supervision practice, the model also has its limitations. Currently, it has yet to be implemented in supervision practice. As a result, evidence is needed to support the effectiveness of this model. In addition, the author's multicultural identity, professional experience, context, and worldview may have influenced the vision for this model. More input is needed from music therapy supervisors and experts internationally before a more refined model can be further developed.

\section{About the author}

Jessica Donley, MMT, MT-BC is the Contracts \& Grants Manager for the Beaver College of Health Sciences at Appalachian State University in Boone, North Carolina. She received her Master of Music Therapy and Systemic Multicultural Counseling Certificate from Appalachian State University in 2017. She continues to explore and research multicultural training and education, culture, and business topics in the music therapy profession.

\section{Notes}

1. This task that was an assignment for a Multicultural Counseling course was originally an assignment by Dr. Mona Mittal, a former professor of professor, Dr. Nickolas Jordan.

\section{References}

Achenbach, K., \& Arthur, N. (2002). Experiential learning: Bridging theory to practice in multicultural counseling. Guidance \& Counseling, 17(2), 39-45.

Ahessy, B. T. (2011). Lesbian, gay, and bisexual issues in music therapy training and education: The love that dares not sing its name. Canadian Journal of Music Therapy, 17(1), 11-33.

Akpovo, S. M., \& Nganga, L. (2018). Minority-world professionals in majority-world early childhood contexts: How do international field experiences promote intercultural competence or reinforce "professional" ethnocentrism? Contemporary Issues in Early Childhood, 19(2), 199-205, https://doi.org/10.1177/1463949118778024.

American Music Therapy Association. (2013). Professional competencies. American Music Therapy Association. https://www.musictherapy.org/about/competencies/.

American Music Therapy Association. (2015a). Advanced competencies. American Music Therapy Association. https://www.musictherapy.org/members/advancedcomp/.

American Music Therapy Association. (2015b). Standards of clinical practice. American Music Therapy Association. https://www.musictherapy.org/about/standards/.

American Music Therapy Association. (2019). Code of ethics. American Music Therapy Association. https://www.musictherapy.org/about/ ethics/?fbclid = IwAR3hGEqtHvaD49K3qWSoCKIf2dngaMPd6UxCpuB4FT4cnQljLr7ILB85sV0. 
Arthur, N., \& Achenbach, K. (2002). Developing multicultural counseling competencies through experiential learning. Counselor Education \& Supervision, 42(1), 2-14, https://dx.doi.org/ 10.1002/j.1556-6978.2002.tb01299.x.

Australian Music Therapy Association. (2014). Code of ethics. Australian Music Therapy Association. https://www.austmta.org.au/codes-of-practice/ethics.

Barak, A. (1990). Counselor training in empathy by a game procedure. Counselor Education and Supervision, 29(3), 170-178, https://doi.org/10.1002/j.1556-6978.1990.tb01152.x.

Baratta, E., Bertolami, M., Hubbard, A., MacDonald, M., \& Spragg, D. (2001). Peer supervision in the development of the new music and expressive therapist. In M. Forinash (Ed.), Music therapy supervision (pp. 181-194). Barcelona Publishers.

Bernard,. (1994). Multicultural counseling supervision: A reaction to Leong and Wagner, Cook, Priest, and Fukuyama. Counselor Education and Supervision, 34(2), 159-171, https://doi.org/ 10.1002/j.1556-6978.1994.tb00323.x.

Bradt, J. (1997). Ethical issues in multicultural counseling: Implications for the field of music therapy. The Arts in Psychotherapy, 24(2), 137-143, https://doi.org/10.1016/ S0197-4556(97)00017-8.

British Association for Music Therapy. (n.d.). BAMT conference 2020 events.https://www.bamt.org/conference/events.html

British Association for Music Therapy. (n.d.). Other courses. https://www.bamt.org/training-inmusic-therapy/other-courses.html

Brown, J. (2002). Towards a culturally centered music therapy practice. Voices: A World Forum for Music Therapy, 2(1), https://doi.org/10.15845/voices.v2i1.72.

Bruscia, K. E. (2002). A psychodynamic orientation to the Bonny method. In K. E. Bruscia \& D. E. Grocke (Eds.), Guided imagery and music: The Bonny method and beyond (pp. 225-243). Barcelona Publishers.

Bruscia, K. (2012). Developing theory. In K. E. Bruscia (Ed.), Readings on music therapy theory (pp. 20-33). Barcelona Publishers.

Bruscia, K. (2014). Defining music therapy. Barcelona Publishers.

Brushke, J. C., Gartner, C., \& Seiter, J. S. (1993). Students' ethnocentrism, dogmaticism, and motivation: A study of BAFA BAFA. Simulation and Gaming, 24(1), 9-20, https://doi.org/ 10.1177\%2F1046878193241003.

Cairde Rince Céilí na hÉireann. (n.d.). What is céili dancing?.https://www.ceilidancing.com/ what-is-ceili-dancing

Canadian Music Therapy Association. (2002). Code of ethics. Canadian Music Therapy Association. https://www.musictherapy.ca/wp-content/uploads/2016/04/ codeofethics99.pdf.

Chazan, S. E. (1990). On being supervised and supervision. In R. Lane (Ed.), Psychoanalytic Approaches to Supervision. Bruner/Mazel.

Clark, M. F. (2002). Evolution of the Bonny method of guided imagery and music (BMGIM). In K. E. Bruscia \& D. Grocke (Eds.), Guided imagery and music: The Bonny method and beyond (pp. 5-27). Barcelona Publishers.

Comte, R. (2016). Neo-colonialism In music therapy: A critical interpretive synthesis of the literature concerning music therapy practice with refugees. Voices: A World Forum for Music Therapy, 16(3), https://doi.org/10.15845/voices.v16i3.865.

Crawley, J., \& Ross, J. (2017). A place for simulation in primary health nursing education: what does it look like? Contemporary Research Topics (Art and Design), 2, 121-128.

Crowe, B. J. (2004). Music and soulmaking: Toward a new theory of music therapy. Scarecrow Press.

Dileo, C. (2000). Ethical thinking in music therapy. Jeffrey Books.

Dileo, C. (2001). Ethical issues in Supervision. In M. Forinash (Ed.), Music therapy supervision (pp. 19-38). Barcelona Publishers. 
Donley, J. (2018). Multicultural experiential learning: An approach to learning, developing, and maintaining multicultural skills. Voices: A World Forum for Music Therapy, 18(2), https://doi.org/10.15845/voices.v18i2.985.

Estrella, K. (2001). Multicultural approaches to music therapy supervision. In M. Forinash (Ed.), Music therapy supervision (pp. 36-66). Barcelona Publishers.

European Music Therapy Confederation. (2005). Ethical codes. European Music Therapy Confederation. http://www.emtc-eu.com/ethical-code/.

Eyre, L. (2001). Theoretical approaches to supervision. In M. Forinash (Ed.), Music therapy supervision (2nd ed., pp. 9-25). Barcelona Publishers.

Feiner, S. (2001). A journey through internship supervision: Roles, dynamics, and phases of the supervisory relationship. In M. Forinash (Ed.), Music therapy supervision (pp. 99-116). Barcelona Publishers.

Forinash, M. (2000). Music therapy supervision. Barcelona Publishers.

Frohne-Hagemann, I. (2001). Integrative techniques in professional music therapy group supervision. In M. Forinash (Ed.), Music therapy supervision (pp. 231-245). Barcelona Publishers.

Gannon, M. J., \& Poon, J. M. (1997). Effects of alternative instructional approaches on crosscultural training outcomes. International Journal of International Relations, 21(4), 429-446, https://doi.org/10.1016/S0147-1767(96)00035-1.

Gullekson, N. L., \& Tucker, M. L. (2013). An examination of the relationships between emotional intelligence and intercultural growth for students studying abroad. Journal of the Academic of Business, 14, 1-17.

Hadley, S., \& Norris, M. (2016). Musical multicultural competency in music therapy: The first step. Music Therapy Perspectives, 34(2), 129-137, https://doi.org/10.1093/mtp/miv045.

Hardy, K. V. (2017). Promoting cultural sensitivity in online and electronically-based supervision. In K. V. Hardy \& T. Bobes. (Eds.),. In K. V. Hardy \& T. Bobes (Eds.), Promoting cultural sensitivity in supervision: A manual for practitioners (pp. 85-97). Routledge.

Hardy, K. V., \& Bobes, T. (2017). Promoting cultural sensitivity in supervision: A manual for practitioners. Routledge.

Hardy, K. V., \& Laszloffy, T. A. (1995). The cultural genogram: Key to training culturally competent family therapists. Journal of Marital and Family Therapy, 21(3), 227-237, https://psycnet.apa.org/doi/10.1111/j.1752-0606.1995.tb00158.x.

Hawkins, P., \& Shohet, R. (2012). Supervision in the helping professions. Open University Press.

Hsiao, F. (2014). Gatekeeping practices of music therapy academic programs and internships: A national survey. Journal of Music Therapy, 51(2), 186-206, https://doi.org/10.1093/jmt/ thu010.

Irish Association of Creative Arts Therapists. (2005). Code of professional conduct and ethics. Irish Association of Creative Arts Therapists. http://www.iacat.ie/code-of-ethics.

Kim, B. S., \& Lyons, H. Z. (2003). Experiential activities and multicultural counseling competence training. Journal of Counseling and Development, 81(4), 400-408, https://doi.org/ 10.1002/j.1556-6678.2003.tb00266.x.

Langdon, G. S. (2001). Experiential music therapy group as a method of professional supervision. In M. Forinash (Ed.), Music therapy supervision (pp. 211-217). Barcelona Publishers.

Kolb, D. (2014). Experiential learning: Experiences as the source of learning and development. Pearson Education.

Murphy, K. (2019). Ethical issues in supervision. In M. Forinash (Ed.). In M. Forinash (Ed.), Music therapy supervision (2nd ed., pp. 27-43). Barcelona Publishers.

National Career Development Association. (2009). Minimum competencies for multicultural career counseling and development. https://www.counseling.org/knowledge-center/competencies.

Neufeldt, S. A. (1999). Supervision strategies for the first practicum (2nd ed.). American Counseling Association. 
New Zealand Music Therapy Registration Board. (2012). Music therapy practice in New Zealand. http://www.musictherapy.org.nz/wp-content/uploads/downloads/2013/02/RegisteredMusic-Therapist-Standards-of-Practice-2012.pdf.

Ngoasheng, A., \& Gachago, D. (2017). Dreaming up a new grid: Two lecturers' reflections on challenging traditional notions of identity and privilege in a South African classroom. Education as Change, 21(2), 187-207, https://doi.org/10.17159/1947-9417/2017/2479.

Norris, M., \& Hadley, S. (2019). Engaging race in music therapy supervision. In M. Forinash (Ed.), Music therapy supervision (2nd ed., pp. 105-125). Barcelona Publishers.

Orozco, G., Lee, W., Blando, J., \& Shooshani, B. (2014). Introduction to multicultural counseling for helping professionals (3rd ed.). Routledge.

Steinwachs, B. (1990). A simulation game of cultural clashes. Intercultural Press.

Stige, B. (2001). The fostering of not-knowing barefoot supervisors. In M. Forinash (Ed.), Music therapy supervision (pp. 161-180). Barcelona Publishers.

Stige, B. (2015). The practice turn in music therapy theory. Music Therapy Perspectives, 33(1), 3-11, https://doi.org/10.1093/mtp/miu050.

Sue, D. W. (1996). Multicultural counseling: Models, methods, and actions. The Counseling Psychologist, 24(2), 279-285, https://doi.org/10.1177\%2F0011000096242008.

Swamy, S. (2011). 'No, she doesn't seem to know anything about cultural differences!': Culturally centered music therapy supervision. Music Therapy Perspectives, 29(2), 133-137, https://doi.org/10.1093/mtp/29.2.133.

Swamy, S., \& Kim, K. A. (2019). Culturally-responsive academic supervision in music therapy. In M. Forinash, Music therapy supervision (2nd ed., pp. 45-58). Barcelona Publishers.

University of the West of England. (2019). Professional course: Supervision training for music therapists.https://courses.uwe.ac.uk/USPKJD30M/supervision-training-for-music-therapists.

Ushida, Y., Hattori, K., \& Takdama, K. (2010). Modeling collective adaptive agent design and its analysis in Barnga game. Journal of Economic Interaction and Coordination, 5(2), 137-154, https://doi.org/10.1007/s11403-010-0070-x.

Vasquez, M. J. T. (1992). Psychologist as clinical supervisor: Promoting ethical practice. Professional Psychology: Research and Practice, 23(3), 196-202, https://psycnet.apa.org/doi/ 10.1037/0735-7028.23.3.196.

YAHAT. (n.d.). Code of ethics. http://www.yahat.org/template/default.aspx?PageId = 76

Young, L. (2009). Multicultural issues encountered in the supervision of music therapy internships in the United States and Canada. The Arts in Psychotherapy, 36(4), 191-201, https://doi.org/10.1016/j.aip.2009.01.004.

Whitehead-Pleaux, A., \& Tan, X. (2017). Cultural intersections in music therapy: Music, health, and the person. Barcelona Publishers.

Whitehead-Pleaux, A. (2019). Culturally-responsive music therapy practice. In M. Forinash (Ed.), Music therapy supervision (2nd ed., pp. 45-58). Barcelona Publishers. 